\title{
Adaptasi Cerpen Chuumon no Ooi Ryouri Ten Karya Miyazawa Kenji Menjadi Anime Karya Shibuichi Setsuko
}

\author{
Fajria Noviana
}

Universitas Diponegoro

fajrianoviana0701@gmail.com

Article History: Submitted date 2018-11-18; Accepted date 2018-11-25; Published date 2018-11-27

\begin{abstract}
This paper is the result of a qualitative descriptive type of literature study. The purpose of this study was to describe what changes Shibuichi Setsuko made in the Chuumon no Ooi Ryouri Ten anime as an adaptation work from Miyazawa Kenji's children's short story with the same title. In addition, it also describes what pedagogical values are contained in this adaptation work. The method used is a comparative method to compare the anime version of the Chuumon no Ooi Ryouri Ten narrative with the short story intrinsic element (Miyazawa, 2014). Meanwhile, based on the four main points of teaching Seikatsuka or life environment studies that applied in Japanese elementary schools, pedagogical values of this anime can be reveal. As a result of the analysis of Shibuichi Setsuko's creative adaptation, four changes were found in the anime version. The four changes lie in the number of characters, characterizations, plot stages, and location setting. Whereas as a result of the analysis of pedagogical values, it is known that this anime fulfills the four main points of the Seikatsuka. This is parallel with Altman's assumption about children's films which suggest that children's film viewers are expected to get teaching, morality, and understanding of identity as a pedagogical experience to improve the quality of life from what they watch.
\end{abstract}

Keywords: adaptation, anime, content analysis, pedagogical values 


\begin{abstract}
Abstrak
Tulisan ini adalah hasil dari penelitian kepustakaan berjenis deskriptif kualitatif. Tujuan penelitian ini adalah untuk mendeskripsikan perubahan apa saja yang dilakukan oleh Shibuichi Setsuko dalam anime Chuumon no Ooi Ryouri Ten sebagai karya adaptasi dari cerpen anak karya Miyazawa Kenji dengan judul sama. Selain itu, juga untuk mendeskripsikan nilai-nilai pedagogis apa saja yang terkandung dalam karya adaptasi ini. Metode yang digunakan adalah metode komparatif untuk membandingkan unsur naratif Chuumon no Ooi Ryouri Ten versi anime dengan unsur intrinsik versi cerpennya. Sementara, untuk mengungkap nilai-nilai pedagogis anime ini digunakan empat poin utama pengajaran Seikatsuka yang diterapkan di sekolah dasar Jepang. Sebagai hasil analisis dari adaptasi kreatif Shibuichi Setsuko, didapatkan empat perubahan yang ada dalam versi anime. Keempat perubahan tersebut terletak pada jumlah tokoh, penokohan, tahapan alur, dan latar tempat. Sedangkan sebagai hasil analisis nilai pedagogis, diketahui bahwa anime ini memenuhi keempat poin utama Seikatsuka. Hal ini sejalan dengan anggapan Altman mengenai film anak yang menyatakan bahwa penonton film anak diharapkan mendapatkan pengajaran, moral, dan pemahaman akan identitas sebagai suatu pengalaman pedagogis untuk meningkatkan kualitas hidup dari apa yang mereka tonton.
\end{abstract}

Kata Kunci: adaptasi, anime, analisis konten, nilai pedagogis

\title{
1. Pendahuluan
}

Adaptasi karya sastra menjadi film merupakan sesuatu yang sudah sejak lama dikembangkan dalam dunia perfilman. Hayward (2006) menyatakan bahwa sejak tahun 1910an, adaptasi sastra kanon menjadi film telah menjadi salah satu cara untuk memasarkan film, yang pada saat itu film menjadi venue of taste bagi produser dan penonton untuk mendapatkan legitimasi (p. 12). Adaptasi karya sastra juga telah berhasil membuat film dianggap sebagai sebuah hiburan yang memiliki nilai seni. Patut dicatat bahwa adaptasi karya sastra menjadi film ini telah secara konsisten memuat nilai-nilai pedagogis yang mengajarkan pada suatu bangsa tentang warisan budayanya, khususnya pada karya sastra klasik (Hayward, 2006).

Sebagai hasil adaptasi, unsur naratif dalam film tersebut tentunya telah mengalami beberapa perubahan sehingga sedikit banyak menjadi berbeda dari karya aslinya. Demikian juga halnya dengan anime berjudul Chuumon no Ooi Ryouri Ten sebagai karya adaptasi Shibuichi Setsuko dari cerpen anak karya Miyazawa Kenji dengan judul sama. Miyazawa Kenji 
(1896-1933) sendiri dikenal sebagai sastrawan yang banyak menghasilkan karya sastra anak. Namun sayangnya, karya-karyanya hanya sedikit mendapat perhatian semasa hidupnya dan justru lebih dikenal setelah ia meninggal dunia (Yamamoto, 2002). Selain Chuumon no Ooi Ryouri Ten, cerpen Miyazawa yang juga diadaptasi menjadi anime atau film antara lain Ginga Tetsudou no Yoru dan Kaze no Matasaburou.

Tulisan ini merupakan upaya untuk mendeskripsikan perubahan apa saja yang dilakukan oleh Shibuichi Setsuko dalam anime Chuumon no Ooi Ryouri Ten sebagai karya adaptasinya. Sebagai sebuah karya adaptasi dari cerpen anak, maka dapat dipastikan bahwa anime ini mengandung banyak nilai pedagogis. Seperti yang dikemukakan oleh Hayward (2006) mengenai adanya muatan nilai-nilai pedagogis dalam adaptasi karya sastra klasik menjadi film, maka tulisan ini juga merupakan upaya untuk mengetahui nilai-nilai pedagogis apa saja yang terkandung dalam anime ini sebagai karya adaptasi Shibuichi Setsuko dari cerpen anak karya Miyazawa Kenji dengan judul sama. Meskipun merupakan cerpen anak, namun sebagian pembaca dewasa (pembaca dewasa yang dimaksud di sini adalah mahasiswa semester IV pada kelas mata kuliah Dokkai di prodi Bahasa dan Kebudayaan Jepang FIB Universitas Diponegoro) merasakan adanya sedikit kengerian saat membaca Chuumon no Ooi Ryouri Ten. Hal senada juga dituliskan dalam informasi mengenai anime berdurasi 21 menit ini, yang meskipun ditujukan bagi segala usia namun disebut bergenre horor, supranatural, dan fantasi ("Chuumon no Ooi Ryouriten (1993)," n.d.). Bagi penulis, ini menjadi hal yang menimbulkan kesan kekurangsesuaian cerpen ini bagi pembaca anak-anak, namun mungkin pada hal inilah terdapat nilai pedagogis utama yang ingin disampaikan oleh Miyazawa Kenji.

Chuumon no Ooi Ryouri Ten bercerita tentang hal-hal aneh yang dialami dua orang pemuda pemburu di dalam hutan setelah mereka terpisah dari pemandu jalan dan kedua ekor anjing yang mereka bawa mati. Hal-hal aneh yang diakibatkan oleh ulah bakeneko penghuni hutan telah membuat mereka ketakutan, sehingga wajah mereka berubah menjadi keriput seperti kakek-kakek. Bakeneko menurut Matthew Meyer adalah mahluk supranatural berwujud kucing yang dapat berubah wujud menjadi manusia dan berbicara dalam bahasa manusia. Saat menjadi manusia, mereka senang mengenakan handuk kecil atau lap di kepalanya (http://yokai.com/bakeneko/). 


\subsection{Adaptasi Karya Sastra}

Dalam A Theory of Adaptation, Hutcheon menyatakan bahwa adaptasi karya sastra terbagi atas tiga perspektif, yaitu sebagai produk, sebagai proses kreatif, dan sebagai proses resepsi (Hutcheon \& O’Flynn, 2013), seperti dijelaskan berikut ini.

a. Adaptasi sebagai produk

Mengalami perubahan bentuk dari satu bentuk karya ke bentuk karya yang lain. Dapat juga dikatakan mengalami transposisi intersemiotik, yakni perubahan dari satu sistem tanda diubah ke dalam sistem tanda yang lain, misalnya dari teks menjadi gambar. Sebagai contoh adalah novel-novel Harry Potter karya J.K. Rowling yang diadaptasi menjadi film layar lebar.

b. Adaptasi sebagai proses kreatif

Apabila novel yang diadaptasi menjadi film mengalami pengurangan (tokoh, plot, dan lainlain), maka cerpen justru mengalami pengembangan. Pengurangan dan pengembangan ini merupakan upaya interpretasi ulang suatu karya untuk menghasilkan karya baru. Sebagai contoh adalah dongeng Si Kancil yang diadaptasi menjadi film animasi dengan berbagai versi cerita.

c. Adaptasi sebagai proses resepsi

Bagi penikmatnya, suatu karya adaptasi akan dihubungkan atau dibandingkan dengan karya-karya lain yang diketahuinya, karena proses resepsi tidak dapat lepas dari proses intertekstual. Teks terdahulu yang melekat pada ingatan penikmat karya adaptasi akan muncul kembali dalam bentuk pengulangan-pengulangan bervariasi. Sebagai contoh adalah pertunjukan balet Swan Lake karya Tchaikovsky yang diadaptasi oleh Matthew Bourne ke dalam nuansa queer (p.15-22), atau menjadi film animasi Amerika berjudul Barbie of Swan Lake karya Owen Hurley.

Selain memiliki tiga perspektif seperti dikemukakan oleh Hutcheon, Hayward (2006) dalam Cinema Studies; The Key Concepts menyatakan bahwa pada dasarnya terdapat tiga tipe adaptasi karya sastra menjadi film. Ketiga tipe tersebut adalah: 1) adaptasi karya sastra klasik; 2) adaptasi drama panggung ke layar lebar; dan 3) adaptasi karya sastra kontemporer, termasuk di dalamnya adalah karya fiksi populer (p. 12). Dari ketiga tipe ini, bagi Hayward tipe kedua dianggap sebagai yang paling setia dengan versi aslinya, meskipun tidak dapat dipungkiri bahwa 
di dalamnya pun terdapat beberapa perubahan sehingga hasil adaptasinya menjadi lebih bernuansa kontemporer. Sebagai contoh adalah drama panggung Romeo and Juliet karya Shakespeare yang diadaptasi menjadi film layar lebar pada tahun 1996 oleh Baz Luhrmann dengan judul sama. Perbedaan antara versi adaptasi dengan versi aslinya adalah pada penggunaan senjata api sebagai pengganti pedang, serta setting yang diubah menjadi persaingan antar kelompok mafia Amerika di wilayah Los Angeles.

Berdasarkan pada pernyataan Hutcheon dan Hayward, maka dapat dikatakan bahwa anime hasil adaptasi cerpen Chuumon no Ooi Ryouri Ten ini merupakan adaptasi kreatif dari cerpen anak kontemporer. Hal ini disebabkan oleh adanya beberapa perbedaan antara versi cerpen dengan versi animenya.

\subsection{Film Anak dan Anime}

Mengutip Bazalgette dan Staples, Wojcik-Andrews dalam Children's Film; History, Ideology, Pedagogy, Theory memberikan definisi mengenai film anak seperti kutipan berikut.

"[First], we explore the idea of cinema for children. This term can mean simply the exhibition of films for a general audience containing some children; it can also mean the dedicated production of films for children. By "children" we mean people under the age of about twelve." (WojcikAndrews, 2000: 1)

Kemudian, pada bagian lain dari bukunya, Wojcik-Andrews mengutip pernyataan Douglas Street bahwa yang dimaksud dengan film anak adalah hasil adaptasi dari karya sastra anak klasik (p. 4). Bagi Street, karya sastra kanon anak telah menarik perhatian para pembuat film yang kemudian mengadaptasinya menjadi film.

Jika mengikuti pernyataan Street, maka anime Chuumon no Ooi Ryouri Ten tidak dapat dimasukkan ke dalam kelompok film anak karena bukan berasal dari karya sastra anak klasik. Namun, mengingat bahwa "Miyazawa Kenji has become one of the most widely read literary figures in Japan" (Yamamoto, 2002), maka dapat dipahami mengapa karya-karya Miyazawa telah berhasil menarik perhatian para produser untuk kemudian mengadaptasinya menjadi film.

Sebagai salah satu genre film, film animasi merupakan jenis film yang banyak digemari anak-anak. Menurut Hayward (2006), Disney Productions merupakan salah satu studio besar yang banyak memproduksi film-film animasi yang tidak hanya dikenal di Amerika tetapi juga di dunia, sehingga gaya animasinya mendominasi animasi Barat (p. 21). Meskipun demikian, 
animasi Jepang atau biasa disebut anime, pun memiliki gaya khas yang berbeda dari film animasi Barat. Orang yang sudah banyak menonton film animasi Barat akan langsung dapat mengetahui perbedaan gayanya dengan anime Jepang. Studio anime yang paling dikenal, baik di dalam maupun di luar Jepang adalah Studio Ghibli. Beberapa anime produksi studio ini telah dialihbahasakan ke dalam bahasa Inggris dan mendapat sambutan hangat oleh penggemar film di luar Jepang, termasuk di negara-negara Barat. Sebagai contoh adalah Spirited Away dan Grave of the Fireflies. Hal ini dimungkinkan karena pada tahun 1996 Walt Disney Enterprise telah membuat perjanjian dengan Studio Ghibli untuk mendistribusikan karya-karya animenya ke Amerika dan Kanada (Napier, 2005).

Menurut Napier, meneliti anime sebagai suatu kekuatan kultural jauh lebih menarik daripada mempertanyakan aspek komersialnya. Hal ini disebabkan oleh fakta bahwa anime "membawa" audiensnya kepada isu yang lebih luas terhadap hubungan antara budaya lokal dan global pada awal abad XXI. Di antara globalisme hegemoni Barat, anime terlihat menonjol sebagai bentuk perlawanan budaya yang implisit. Anime merupakan produk artistik yang unik; sebuah wujud lokal dari budaya pop yang menampilkan akar budaya Jepang dengan jelas (p. 9).

\subsection{Nilai Pedagogis}

Dalam Kamus Besar Bahasa Indonesia daring, kata nilai didefinisikan salah satunya sebagai "sifat-sifat (hal-hal) yang penting atau berguna bagi kemanusiaan”(“Arti kata nilai Kamus Besar Bahasa Indonesia (KBBI) Online," n.d.), sedangkan kata pedagogis didefinisikan sebagai "sesuatu yang bersifat mendidik" (“Arti kata pedagogis - Kamus Besar Bahasa Indonesia (KBBI) Online," n.d.). Jadi, nilai pedagogis dapat diartikan sebagai nilai yang bersifat mendidik. Sementara, kata mendidik didefinisikan sebagai "memelihara dan memberi latihan (ajaran, tuntunan, pimpinan) mengenai akhlak dan kecerdasan pikiran".

Dalam hubungannya dengan mendidik anak, Ishii Yuri dalam bukunya yang berjudul Development Education in Japan; a Comparative Analysis of the Contexts for Its Emergence and Its Introduction Into the Japanese School System menyebutkan bahwa Departemen Pendidikan Jepang telah menghapuskan studi sosial dan ilmu alam di dua tahun pertama sekolah dasar dan memperkenalkan mata pelajaran baru yang disebut Seikatsuka pada tahun 1987 (Ishii, 2003). Seikatsuka atau disebut juga life environment studies adalah mata pelajaran gabungan dari 
studi sosial dan ilmu alam, yang diberikan pada siswa kelas I dan II sekolah dasar. Mata pelajaran ini dimasukkan ke dalam kurikulum nasional Jepang pada tahun 1989. Menurut Nakano Shigeto sebagai kontributor utama Seikatsuka, tujuan mata pelajaran ini adalah untuk pengembangan diri anak. Untuk mencapai tujuan ini, terdapat empat poin utama Seikatsuka yang harus dipenuhi, yaitu: 1) memberikan kegiatan dan pengalaman konkret yang penting dalam proses belajar anak; 2) membuat anak dapat melihat hubungan mereka dengan masyarakat dan alam; 3) membuat anak menghargai kepedulian; dan 4) meningkatkan pemerolehan anak akan kebiasaan dan keterampilan yang diperlukan dalam kehidupan seharihari (p. 98).

Sementara, dalam hubungannya dengan film anak, menurut Dole dan Hays (Beeler \& Beeler, 2015) film anak diasumsikan memiliki nilai bagi masyarakat, sehingga film anak akan dihargai jika menampilkan fungsi budaya dan fungsi pedagogis, sebagaimana tugas pengajar/guru, pendeta/agamawan, dan pengarang/sastrawan. Sementara, Altman beranggapan bahwa film anak merupakan intervensi dalam struktur tipe penonton, dan penonton diasumsikan terpengaruh secara mendalam oleh pengalaman menonton mereka. Para penonton, baik anak-anak maupun orangtua, diharapkan mendapatkan sesuatu dari apa yang mereka tonton, lebih dari sekedar hiburan atau kesenangan menonton belaka. Sesuatu tersebut adalah pengajaran, moral, dan pemahaman akan identitas sebagai suatu pengalaman pedagogis untuk meningkatkan kualitas hidup. Oleh karena itu, pengaruh ideologis atau pedagogis dalam film anak umumnya cukup terang benderang; tidak diperhalus sebagaimana dalam film untuk selain anak (p. 10-11).

Pendapat Dole dan Hays di atas tidak lebih dari pengulangan akan apa yang sudah dipercayai sejak lama, yaitu bahwa cerita anak sudah seharusnya mengandung muatan pedagogis. Dalam buku yang sama, Shavit menambahkan bahwa buku-buku untuk anak harus pantas secara pedagogis dan memiliki sumbangsih bagi perkembangan emosi dan sosial anak. Gagasan ini hingga kini masih terus mendominasi dalam bidang produksi budaya. Hal ini terbukti dari sangat banyaknya jumlah cerita anak-anak yang menekankan pada adanya heroisme personal, perkembangan individu, dan pembentukan identitas, dibandingkan dengan jumlah cerita anak-anak yang berkisah tentang sejarah atau aktifitas kolektif (p. 11). 


\subsection{Metode Penelitian}

Penelitian ini adalah penelitian kepustakaan berjenis deskriptif kualitatif. Karena merupakan studi kepustakaan, maka semua data didapatkan dari berbagai sumber tertulis, baik tercetak maupun daring. Anime yang digunakan dalam penelitian ini diunduh dari https: //myanimelist.net/anime/30967/Chuumon_no_Ooi_Ryouriten_1993?q=chuumon. Sementara, versi cerpennya diambil dari レベル別; 日本語多読ライブラリー level 3, yang digunakan dalam kelas mata kuliah Dokkai semester IV.

Metode yang digunakan dalam analisis untuk mendapatkan jawaban dari permasalahan yang diangkat adalah metode komparatif. Dengan metode ini, struktur naratif pembangun anime Chuumon no Ooi Ryouri Ten dikomparasikan dengan unsur intrinsik cerpennya, sehingga perubahan-perubahan yang dilakukan Shibuichi Setsuko terhadap cerpen Miyazawa Kenji dapat diketahui. Selain itu, dengan didasarkan pada empat poin utama pengajaran Seikatsuka, maka nilai pedagogis apa saja yang terdapat dalam anime ini pun dapat diungkap. Empat poin utama pengajaran Seikatsuka ini dipilih untuk mengungkap nilai pedagogis yang terdapat dalam anime Chuumon no Ooi Ryouri Ten karena dua hal. Pertama, baik versi cerpen maupun versi anime ini ditujukan bagi segala usia dengan anak-anak sebagai sasaran utamanya. Yang dimaksud dengan anak-anak sebagai audiens dari film anak adalah mereka yang berusia dua belas tahun ke bawah (Wojcik-Andrews, 2000). Kedua, Seikatsuka dimasukkan ke dalam kurikulum nasional Jepang pada tahun 1989 dan masih terus digunakan hingga saat ini, sehingga dianggap tepat untuk menggali nilai pedagogis yang terdapat dalam versi anime dari cerpen anak yang dirilis pada tahun 1993 ini.

\section{Hasil dan Pembahasan}

Hasil dan pembahasan ini dibagi ke dalam dua bagian, yaitu yang membahas perubahan apa saja yang dilakukan oleh Shibuichi Setsuko dalam anime Chuumon no Ooi Ryouri Ten sebagai hasil adaptasi kreatif, serta nilai pedagogis yang terdapat dalam anime ini.

\subsection{Perubahan Sebagai Adaptasi Kreatif}


Sebagai sebuah hasil adaptasi kreatif, anime Chuumon no Ooi Ryouri Ten memiliki beberapa perubahan yang membuatnya sedikit berbeda dari versi cerpennya. Perbedaan tersebut ditampilkan dalam tabel dan dijelaskan sebagai berikut.

Tabel 1: Perbedaan versi anime dengan versi cerpen

[Hasil analisis]

\begin{tabular}{|c|c|c|c|}
\hline No. & Perbedaan & Cerpen & Anime \\
\hline 1. & $\begin{array}{l}\text { Pelaku } \\
\text { cerita/tokoh }\end{array}$ & $\begin{array}{l}\text { - Dua orang pemburu } \\
\text { - Seorang pemandu } \\
\text { - Kucing hutan yang tidak riil } \\
\text { (bakeneko) }\end{array}$ & $\begin{array}{l}\text { - Dua orang pemburu } \\
\text { - Seorang pemandu } \\
\text { - Kucing hutan, baik riil } \\
\text { maupun tidak riil (bakeneko) }\end{array}$ \\
\hline 2. & $\begin{array}{l}\text { Penokohan } \\
\text { a. Pemburu }\end{array}$ & Dua orang pemuda & $\begin{array}{l}\text { Dua orang laki-laki, satu orang } \\
\text { bertubuh tinggi kurus, satu } \\
\text { orang bertubuh pendek gemuk }\end{array}$ \\
\hline \multirow{5}{*}{3.} & b. Pemandu & Manusia biasa & $\begin{array}{l}\text { Bukan manusia yang } \\
\text { sesungguhnya }\end{array}$ \\
\hline & c. Kucing hutan & $\begin{array}{l}\text { Tidak disebutkan dengan jelas. } \\
\text { Hanya ditampilkan sebagai bola } \\
\text { mata kucing berwarna biru, } \\
\text { berukuran besar, dan mengeong } \\
\text { seperti kucing pada umumnya }\end{array}$ & $\begin{array}{l}\text { Bertingkah laku seperti manusia } \\
\text { dan dapat berbicara. Beberapa } \\
\text { tokoh ini muncul dengan } \\
\text { berbagai ukuran tubuh, mulai } \\
\text { dari ukuran kucing hutan normal } \\
\text { hingga raksasa }\end{array}$ \\
\hline & \multirow{2}{*}{$\begin{array}{l}\text { Peristiwa dan } \\
\text { konflik/tahapan } \\
\text { alur } \\
\text { a. Pengenalan }\end{array}$} & & \\
\hline & & $\begin{array}{l}\text { Dua orang pemburu, seorang } \\
\text { pemandu, dan dua ekor anjing } \\
\text { memasuki hutan untuk memulai } \\
\text { perburuan }\end{array}$ & $\begin{array}{l}\text { Dua orang pemburu, seorang } \\
\text { pemandu, dan dua ekor anjing } \\
\text { memasuki hutan untuk memulai } \\
\text { perburuan. Di saat itulah, seekor } \\
\text { kucing hutan yang sedang } \\
\text { beristirahat di atas pohon } \\
\text { menunjukkan } \\
\text { ketidaksenangannya akan } \\
\text { kedatangan kedua pemburu }\end{array}$ \\
\hline & $\begin{array}{l}\text { b. Kemunculan } \\
\text { konflik }\end{array}$ & $\begin{array}{l}\text { Pemandu menghilang dan } \\
\text { kedua ekor anjing mati. Lalu } \\
\text { kedua pemburu yang } \\
\text { tersesat dan kelaparan }\end{array}$ & $\begin{array}{l}\text { Pemandu menghilang dan } \\
\text { kedua ekor anjing mati. Lalu } \\
\text { kedua pemburu yang tersesat } \\
\text { dan kelaparan menemukan }\end{array}$ \\
\hline
\end{tabular}




\begin{tabular}{|c|c|c|c|}
\hline & & $\begin{array}{l}\text { menemukan restoran di } \\
\text { dalam hutan }\end{array}$ & $\begin{array}{l}\text { restoran di dalam hutan } \\
\text { - Gambar kucing yang ada } \\
\text { dalam papan nama restoran } \\
\text { melompat ke luar dan } \\
\text { mengamati tingkah laku } \\
\text { kedua pemburu yang datang } \\
\text { - Munculnya bayangan kepala } \\
\text { kucing hutan raksasa di } \\
\text { cermin yang sedang } \\
\text { digunakan oleh pemburu } \\
\text { pendek gemuk }\end{array}$ \\
\hline & c. Klimaks & $\begin{array}{l}\text { Bola mata kucing berwarna biru } \\
\text { dan berukuran besar mengamati } \\
\text { kedua pemburu melalui lubang } \\
\text { kunci yang juga berukuran besar }\end{array}$ & $\begin{array}{l}\text { Bola mata kucing berwarna } \\
\text { biru dan berukuran besar } \\
\text { mengamati kedua pemburu } \\
\text { Dengan menggunakan kaki } \\
\text { depannya, } 2 \text { kucing raksasa } \\
\text { berusaha meraih kedua } \\
\text { pemburu yang ketakutan }\end{array}$ \\
\hline & d. Anti klimaks & $\begin{array}{l}\text { Pemandu menemukan kedua } \\
\text { pemburu }\end{array}$ & $\begin{array}{l}\text { Pemandu menemukan kedua } \\
\text { pemburu. Ternyata, pemandu } \\
\text { kedua pemburu ini adalah } \\
\text { bakeneko yang menjelma } \\
\text { menjadi manusia }\end{array}$ \\
\hline 4. & $\begin{array}{l}\text { Hubungan naratif } \\
\text { dengan } \\
\text { ruang/latar } \\
\text { tempat }\end{array}$ & $\begin{array}{l}\text { - Di balik pintu pertama tidak } \\
\text { terdapat tulisan } \\
\text { - Pintu terakhir berukuran } \\
\text { sama seperti pintu-pintu } \\
\text { lainnya, namun memiliki } \\
\text { lubang kunci yang sangat } \\
\text { besar }\end{array}$ & $\begin{array}{l}\text { - Terdapat tulisan di balik pintu } \\
\text { pertama tentang betapa } \\
\text { senangnya pihak restoran jika } \\
\text { pengunjungnya bertubuh } \\
\text { gemuk dan masih muda } \\
\text { - Pintu terakhir sangat tinggi } \\
\text { dan tidak memiliki lubang } \\
\text { kunci, namun bagian atasnya } \\
\text { memiliki semacam jendela } \\
\text { yang dapat dibuka }\end{array}$ \\
\hline
\end{tabular}

Pada poin tokoh, terdapat penambahan tokoh dalam versi anime karya Shibuichi Setsuko ini, yaitu tokoh kucing hutan yang riil,yang betul-betul merupakan binatang kucing sesungguhnya. Selain kucing hutan riil, terdapat juga bakeneko seperti pada versi cerpennya. Meskipun berwujud binatang, namun bakeneko ini bukanlah binatang sesungguhnya karena dalam penokohannya digambarkan dalam berbagai wujud. Mulai dari wujud kucing hutan biasa 
berukuran normal hingga berukuran raksasa, gambar-gambar kucing dua dimensi yang ternyata hidup, hingga bayangan kucing raksasa yang membuntuti dua orang pemburu yang masuk ke dalam restoran tersebut. Selain itu, kucing-kucing hutan ini pun bertingkah laku seperti manusia dan dapat berbicara dalam bahasa manusia. Mereka selalu mengamati segala tindak-tanduk dua orang laki-laki pemburu yang datang ke restoran, menakut-nakuti kedua pemburu ini, bahkan membujuk kedua pemburu ini agar mau masuk ke ruangan terakhir restoran tersebut, dengan menggunakan bahasa manusia.

Selain penambahan tokoh dengan penokohannya, terdapat beberapa perubahan pada penokohan kedua laki-laki pemburu dan pemandu mereka. Dalam versi anime, kedua pemburu ini ditampilkan sebagai dua orang laki-laki berusia sekitar 30-an tahun. Satu orang bertubuh tinggi kurus, dan satu orang lagi bertubuh pendek gemuk. Sedangkan dalam versi cerpennya, kedua pemburu ini hanya disebutkan sebagai 若い男が二人 (dua orang laki-laki muda). Sementara, tokoh pemandu kedua pemburu ini pada tahap pengenalan ditampilkan sebagai seorang laki-laki biasa, sedangkan pada tahap anti klimaks ternyata ditunjukkan sebagai penjelmaan dari bakeneko.

Perubahan berikutnya terletak pada tahapan alur. Pada tahap pengenalan versi anime, diperlihatkan seekor kucing hutan yang sedang beristirahat di atas pohon yang menggeram saat melihat kedatangan dua orang pemburu ke hutan. Dengan sangat jelas, ia menunjukkan ketidaksenangannya pada kedua pemburu tersebut. Sedangkan dalam versi cerpen, peristiwa ini tidak ada. Kemudian dalam tahap kemunculan konflik, pada versi anime ditampilkan adegan berupa gambar kucing yang ada pada papan nama restoran menjadi hidup dan melompat ke luar dari papan nama, lalu dengan menyeringai ia mengamati segala tindak-tanduk kedua pemburu yang masuk ke dalam restoran tersebut. Selain adegan tersebut, ditampilkan juga adegan munculnya bayangan kepala kucing hutan raksasa di cermin yang sedang digunakan oleh pemburu yang berpostur pendek gemuk saat ia menyisir rambutnya sambil bercermin. Kedua hal ini tidak ada dalam versi cerpennya.

Hal yang juga hanya ada dalam versi anime pada tahapan alur lainnya terletak pada bagian klimaks dan anti klimaks. Pada bagian klimaks, saat kedua pemburu berusaha mencari 
jalan untuk menyelamatkan diri setelah menyadari bahwa merekalah hidangan yang akan disajikan di restoran tersebut, muncul bayangan kucing raksasa di bagian atas pintu terakhir yang sangat tinggi. Bagian atas pintu tersebut terbuat dari kaca yang dietsa. Di bagian bawah kaca etsa itu terdapat semacam jendela yang tiba-tiba terbuka. Dari empat lubang jendela tersebut, dua kepala kucing hutan raksasa dan dua kaki depan mereka yang sangat besar menjulur masuk ke dalam ruangan di mana kedua pemburu tersebut terperangkap. Kucingkucing hutan tersebut awalnya membujuk kedua pemburu untuk melewati pintu terakhir, tapi karena kedua pemburu itu justru menangis ketakutan, maka kedua kucing hutan tersebut berusaha meraih untuk menangkap mereka. Kemudian, pada bagian anti klimaks, saat kedua pemburu berjalan meninggalkan hutan bersama dua ekor anjing dan pemandu, si pemandu menoleh ke belakang dan memberi salam pada rusa-rusa yang sebenarnya ingin dijadikan target buruan. Tanpa diketahui oleh kedua pemburu, tiba-tiba secara sekilas wajah si pemandu berubah menjadi wajah kucing hutan yang menyeringai.

Perubahan terakhir terletak pada hubungan naratif dengan ruang atau latar tempat. Terdapat dua hal yang tidak ada pada versi cerpennya. Pertama, tulisan di belakang pintu pertama yang berbunyi「ことに肥えたお方や若いお方は大歓迎いたします」 yang berarti "Kami menyambut dengan gembira kepada yang bertubuh gemuk dan masih muda". Kedua, pintu terakhir dalam restoran tersebut sangat tinggi dan tidak memiliki lubang kunci, namun bagian atasnya memiliki semacam jendela yang dapat dibuka. Dari jendela inilah kepala kucing hutan raksasa dan kaki depannya menjulur masuk untuk meraih kedua pemburu tersebut.

\subsection{Nilai Pedagogis}

Nilai pedagogis yang dituliskan di sini berdasarkan pada empat poin yang harus terpenuhi dalam mata pelajaran Seikatsuka di sekolah dasar karena anime ini diadaptasi berdasarkan cerpen anak, dengan batasan anak menurut Bazalgette dan Staples adalah yang masih berusia di bawah dua belas tahun (Wojcik-Andrews, 2000). Oleh karena itu, orangtua dan guru disarankan untuk mendampingi anak saat mereka menonton anime ini. Nilai pedagogis yang dapat diperoleh dari hasil analisis anime ini adalah sebagai berikut.

1. Memberikan kegiatan dan pengalaman konkret yang penting dalam proses belajar anak. 
Dengan menonton anime ini dengan didampingi orangtua atau guru, anak akan belajar untuk mengemukakan pendapatnya, belajar untuk mendengarkan pendapat orang lain, serta belajar membedakan baik dan buruk. Sebagai contoh adalah dengan menanyakan kesan anak setelah menonton anime ini, apa pendapat anak mengenai kedua pemburu dalam anime ini, dan lain-lain.

2. Membuat anak dapat melihat hubungan mereka dengan masyarakat dan alam.

Dengan menonton anime ini, anak akan mengetahui bahwa manusia merupakan mahluk sosial; ia tidak bisa hidup sendiri tanpa keberadaan orang lain. Hal ini diperlihatkan dalam peristiwa di mana kedua pemburu tersesat dan kebingungan karena ketiadaan si pemandu, baik saat sebelum mereka masuk ke dalam restoran dan terutama setelah mereka mengalami kejadian yang mengerikan.

Selain itu, anak juga akan mengetahui pentingnya menjaga dan menyayangi alam dan mahluk hidup lain di dalamnya. Hal ini diperlihatkan dalam peristiwa ketika kedua pemburu merasa ketakutan dan putus asa karena merasa akan menjadi santapan bakeneko, tiba-tiba kedua ekor anjing yang mereka tinggalkan menerjang masuk untuk menolong mereka. Kedua ekor anjing ini ditinggalkan begitu saja di hutan oleh kedua pemburu ini karena mereka menganggap anjingnya telah mati setelah berkelahi melawan suatu binatang dalam semak-semak. Kedua orang ini sama sekali tidak memikirkan anjing mereka, tapi justru menyayangkan uang yang sudah mereka keluarkan untuk membeli kedua ekor anjing ini. Hal ini pun sekaligus dapat menjadi contoh penilaian anak terhadap baik buruknya suatu tindakan.

3. Membuat anak menghargai kepedulian.

Dengan menonton anime ini dengan didampingi orangtua atau guru, anak akan belajar untuk lebih peduli pada diri, orang lain, dan lingkungan sekitarnya. Penghargaan akan kepedulian ini dimaksudkan agar anak lebih waspada pada apa yang dikenakan, dikonsumsi, atau apa yang mungkin terjadi bila mereka melakukan sesuatu. Hal ini disampaikan melalui tingkah laku kedua pemburu yang menuruti semua yang tertulis di pintu-pintu yang ada di sepanjang lorong restoran tanpa berpikir panjang. 
4. Meningkatkan pemerolehan anak akan kebiasaan dan keterampilan yang diperlukan dalam kehidupan sehari-hari.

Dengan menonton anime ini dengan didampingi orangtua atau guru, setelah menonton anak akan dapat belajar untuk menceritakan ulang apa yang sudah ditontonnya; atau dengan kata lain pengalamannya. Anak akan belajar untuk membiasakan diri untuk menceritakan segala hal yang dialaminya kepada orangtua dan gurunya. Hal ini sangat penting agar anak terhindar dari kemungkinan terkena atau terpapar sesuatu yang berbahaya atau tidak pantas.

\section{Simpulan}

Dari paparan pada subbab sebelumnya, diketahui bahwa anime Chuumon no Ooi Ryouri Ten sebagai karya hasil adaptasi cerpen anak dengan judul sama telah mengalami beberapa perubahan yang bervariasi, yaitu pada pelaku cerita atau tokoh, penokohan, peritiwa dan konflik atau tahapan alur, dan pada hubungan naratif dengan ruang atau latar tempat. Sementara, pada hasil analisis nilai pedagogis dengan menggunakan poin-poin pengajaran Seikatsuka, diketahui bahwa keempat poin tersebut terdapat pada anime ini. Hal ini sejalan dengan anggapan Altman mengenai film anak yang menyatakan bahwa penonton film anak diharapkan mendapatkan pengajaran, moral, dan pemahaman akan identitas sebagai suatu pengalaman pedagogis untuk meningkatkan kualitas hidup dari apa yang mereka tonton.

Hal lain yang dapat diketahui setelah mengkomparasikan anime ini dengan versi cerpennya adalah bahwa versi animenya sama sekali tidak menimbulkan kengerian pada penonton dewasa, berbeda dengan versi cerpennya. Bisa jadi hal ini merupakan akibat dari tampilan bakeneko yang tampak jelas memiliki wujud kucing hutan. Berbeda dengan versi cerpennya, bakeneko sama sekali tidak digambarkan selain sebagai bola mata besar berwarna biru yang mengintip kedua pemburu melalui lubang kunci yang berukuran besar pula. Diakui atau tidak, hal-hal yang bersifat samar-samar atau tidak pasti umumnya lebih ditakuti oleh orang dewasa daripada oleh anak-anak. Orang dewasa umumnya menginginkan segala sesuatu 
tampak jelas dan rasional, sehingga hal-hal yang tidak memenuhi kualifikasi tersebut akan dapat membuat mereka khawatir.

\section{Daftar Pustaka}

Arti kata nilai - Kamus Besar Bahasa Indonesia (KBBI) Online. (n.d.).

Arti kata pedagogis - Kamus Besar Bahasa Indonesia (KBBI) Online. (n.d.).

Beeler, Karin \& Beeler, S. (2015). Children's Film in the Digital Age; Essays on Audience, Adaptation, and Consumer Culture. Jefferson, North Carolina: McFarland \& Company, Inc., Publishers.

Chuumon no Ooi Ryouriten (1993). (n.d.). Retrieved from https://myanimelist.net/anime/30967/Chuumon_no_Ooi_Ryouriten_1993

Hayward, S. (2006). Cinema Studies; The Key Concepts (3rd ed.). Oxon: Routledge. Hutcheon, Linda \& O'Flynn, S. (2013). A Theory of Adaptation (2nd ed.). Oxon: Routledge.

Ishii, Y. (2003). Development Education in Japan; a Comparative Analysis of the Contexts for Its Emergence and Its Introduction Into the Japanese School System. New York: RoutledgeFalmer.

Miyazawa, K. (2014). 注文の多い料理店：レベル別日本語多読ライブラリー. Tokyo: Ask Publising.

Napier, S. J. (2005). Anime, From Akira to Howl's Moving Castle: Experiencing Contemporary Japanese Animation. New York: Palgrave MacMillan.

Wojcik-Andrews, I. (2000). Children Films; History, Ideology, Pedagogy, Theory. New York: Garland Publishing, Inc.

Yamamoto, M. (2002). 宮沢賢治とは誰か? Retrieved from http://www.kenjiworld.net/who/who.html 